\section{Sudden cardiac death in young athletes: Literature review of molecular basis}

Cristina Mazzaccara, ${ }^{1,2}$ Bruno Mirra, ${ }^{1,2}$

Ferdinando Barretta, 1,2

Barbara Lombardo, ${ }^{1,2}$ Olga Scudiero, ${ }^{1,2}$

Giulia Frisso $^{1,2}$

${ }^{1}$ Department of Molecular Medicine and

Medical Biotechnology, University of

Naples Federico II; ${ }^{2}$ CEINGE Advanced

Biotechnologies, Naples, Italy

\section{Abstract \\ Intense athletic training and competi-} tion can rarely result in sudden cardiac death (SCD). Despite the introduction of pre-participation cardiovascular screening, especially among young competitive athletes, sport-related SCD remains a debated issue among medical personnel, sports communities and laypersons alike, and generates significant media attention. The most frequent cause of SCD is a hidden inherited cardiomyopathy, the athletes may not even be aware of. Predictive medicine, by searching the presence of pathogenic alterations in cardiac genes, may be an integrative tool, besides the conventional ones used in cardiology (mainly electro and echocardiogram), to reach a definitive diagnosis in athletes showing signs/symptoms, even borderline, of inherited cardiomyopathy/channelopathy, and in athletes presenting family history of SCD and/or of hereditary cardiac disease. In this review, we revised the molecular basis of the major cardiac diseases associated to sudden cardiac death and the clinical molecular biology approach that can be used to perform risk assessment at DNA level of sudden cardiac death, contributing to the early implementation of adequate therapy. Alterations can occur in ion channel genes, in genes encoding desmosomal and junctional proteins, sarcomeric and Z-disc proteins, proteins for the cytoskeleton and the nuclear envelope. The advent of next generation sequencing (NGS) technology has provided the means to search for mutations in all these genes, at the same time. Therefore, this molecular approach should be the preferred methodology for the aforementioned purpose.

\section{Introduction}

Regular physical activity is a powerful tool for improving health and helps to pre- vent many disorders, including cardiovascular risk factors, obesity, depression, anxiety, musculoskeletal problems and stress. ${ }^{1-3}$ Numerous epidemiological studies have shown an association between moderate aerobic exercise and decreased risk of coronary heart disease, ${ }^{4-6}$ reduced risk of ventricular fibrillation in patients affected by a first myocardial infarction, ${ }^{7,8}$ as well as a reduction of overall death and cardiovascular mortality in cardiac patients subjected to adequate training programs. ${ }^{9,10}$ Furthermore the use of biochemical and haematological tests to evaluate risk factors in athlete is of relevance and interest at the amateur, competitive and elite level. ${ }^{11}$

However, for a small number of individuals physical exercise can increase the risk of sudden cardiac death (SCD). ${ }^{12,13}$ In particular, vigorous activity can transiently increase the risk of SCD in asymptomatic young athletes carrying genetic mutations predisposing to arrhythmic diseases. ${ }^{14,15}$

Sudden cardiac death is the most frequent medical cause of sudden death in athletes. Estimates vary widely based on the analyzed population, sports-associated SCD represents about $6 \%$ of the overall SCD burden. ${ }^{16,17}$ In Europe and North America the incidence of SCD is 2 athletes of 100,000 per year. ${ }^{18}$ In the Veneto region of Northern Italy, where $>110,000$ athletes were evaluated over a 21-year follow-up period, the incidence of SCD was 2.6/100,000 personyears in male athletes and 1.1/100,000 person-years in their female counterparts. ${ }^{13}$ The incidence varied by sex, the risk of SCD being higher in men than in women. ${ }^{15}$ Some athlete subgroups, specifically African Americans, male basketball and football players, appear to be at higher risk in the United States, whereas male soccer players had a higher incidence of SCD than other athletes in Europe. ${ }^{18,19}$ This observation suggests that individuals participating in sports of high dynamic and low isometric intensity are at higher risk of death.

Few studies report prevalence of sportsrelated sudden death in the general population. Of note, paper of Marijon et al. showed that only $6 \%$ of sports-related sudden death in the general population occur in young competitive athletes, the remaining involving amateur athletes. ${ }^{20}$

Though SCD is rare, its occurrence in athletes who are often young and presumably healthy has a large emotional and social impact on the surrounding community. Therefore, considerable effort has been made to better understand the causes of SCD in athletes and to discover optimal strategies for prevention.

To this aim, the clinical molecular biology laboratory has acquired an increasingly
Correspondence: Giulia Frisso and Cristina Mazzaccara, Department of Molecular Medicine and Medical Biotechnology/ CEINGE- Advanced Biotechnologies, Via Pansini 5, 80131 Naples, Italy.

Tel.: $+39.081 .7462405 ;+39.081 .7462422$

Fax: +39.081.7462404.

E-mail: gfrisso@unina.it;

cristina.mazzaccara@unina.it

Key words: Sudden cardiac death; cardiomyopathy; genetic testing; athletes.

Contributions: GF, CM, BM; wrote the manuscript and approved the final version; FB, BL, OS; involved in literature data collection. All authors critically reviewed the manuscript.

Funding: the authors declare that no sources of funding were used in the preparation of this review.

Conflict of interest: the authors declare no conflict of interests.

Received for publication: 31 January 2020.

Revision received: 24 March 2020.

Accepted for publication: 27 March 2020.

This work is licensed under a Creative Commons Attribution NonCommercial 4.0 License (CC BY-NC 4.0).

C Copyright: the Author(s), 2020

Licensee PAGEPress, Italy

Cardiogenetics 2020; 10:8860

doi:10.4081/cardiogenetics.2020.8860

relevant role for the early identification of molecular alterations that can be causative or con-causative of SCD in athletes. ${ }^{21}$ It is important to identify the specific DNA defect associated with a clinically manifest heart disease in an athlete, and, above all, to recognize the possible individual predisposition to develop a latent heart disease, before the disease can manifest itself with the fatal event of SCD.

In this review we will discuss genetic causes of sudden cardiac death in athletes, with particular emphasis on challenges in molecular diagnostics of inherited cardiac disease, like channelopathy and cardiomyopathy.

\section{Cardiac diseases in young athletes}

Cardiac diseases associated with SCD differ in young $v s$ older athletes, the SCD cause being elusive even after autopsy in young subjects. Guidelines of the European Society of Cardiology (ESC) encouraged molecular autopsy ${ }^{22}$ in addition to the standard autopsy, as it may allow the post- 
mortem diagnosis of cardiac channelopathies, which explain $15-25 \%$ of sudden arrhythmic deaths. The most common causes of sport-related SCD in adolescents and young adults are inherited cardiomyopathies,,$^{18,23-31}$ a clinically heterogeneous group of heart muscle disorders, characterized by the presence of abnormal myocardial structure and/or function, in the absence of ischemic heart disease or abnormal loading conditions. ${ }^{32}$

Arrhythmogenic cardiomyopathy (ACM) has been reported to account for approximately $25 \%$ in Italy, whereas it accounts for only $6 \%$ of cases in the USA. ${ }^{13,25,33,34}$ By contrast, hypertrophic cardiomyopathy (HCM) is one of the leading causes of SCD among athletes in the USA, where it has been reported to accounting for more than $30 \%$ of fatal cases, ${ }^{9,22,28}$ while in European studies HCM is reported to cause less than $10 \%$ of SCDs. ${ }^{29}$ These divergences are attributable to the heterogeneity of relative frequencies in various countries, to the different diagnostic and autopsy procedures used $^{18}$ and probably they are mainly due to the different protocols of sports activity preparticipation screening. Electrocardiography (ECG) screening is a common practice in most European countries and is compulsory in Italy and Israeli, ${ }^{18,35}$ but it is not routinely performed in the USA. The ECG inclusion into the athlete screening protocol improves efficacy to identify asymptomatic athletes who have a potentially lethal cardiomyopathy, ECG findings being abnormal in $90 \%$ of HCM patients, ${ }^{36}$ and protect them from the risk of SCD through restriction from competitive sports.

However, as reported in recent literature $\mathrm{e}^{21,27,37,38}$ the most common cardiomyopathies related to $\mathrm{SCD}$, are the inherited ion channel diseases, followed by ACM, HCM and dilated cardiomyopathy (DCM).

\section{Genetic basis of cardiac diseases in athletes}

In the last two decades the knowledge of molecular basis of cardiomyopathies has progressively increased: actually mutations in more than 200 genes are associated to cardiomyopathies, such as sarcomeric and cytoskeleton genes (particularly related to HCM and DCM), desmosomal genes (involved in ACM), ion channel genes (channelopathies). ${ }^{39-49}$ Mutations are mainly inherited in an autosomal dominant pattern, although Xlinked, autosomal recessive, or matrilineal inheritance may also occur in a minority of cases..$^{32,50}$
Inherited cardiomyopathies are characterized by both allelic heterogeneity, which occurs when mutations within the same gene can produce different phenotypes, and genetic heterogeneity, occurring when mutations within different genes produce the same phenotype.

For example, SCN5A gene mutations are associated with distinct channelopathies, such as long QT syndrome, Brugada syndrome, and also to $\mathrm{HCM}$ or DCM. ${ }^{51}$ Instead, DCM may be caused by mutations in sarcomeric, cytoskeletal, gap junction and even ion channel genes. Variable penetrance and incomplete expression are common in all cardiomyopathies, even among related subjects sharing the same pathogenic allele, ${ }^{52,53}$ and may reflect the action of modifier genes, epigenetic changes, environmental factors, or other factors such as age, gender, ethnicity or physical activity. To establish the diagnosis of inherited cardiomyopathy, the elucidation of family history and comprehensive assessment of pedigree is the foremost necessity, but it may not be sufficient. Electrocardiography, echocardiography and cardiac magnetic resonance imaging may not reveal subclinic anomalies present in asymptomatic subjects harbouring mutations. ${ }^{54}$ Thus, genetic test in the proband and cascade family screening is a valuable tool to exactly diagnose an inherited cardiomyopathy and to identify family members at disease-risk in preclinical stage. ${ }^{55}$ Furthermore, bioinformatics approach and functional studies can help to predict the pathogenicity of new variants found during genetic screening. ${ }^{56,57}$

In this regard, ESC and American Heart Association (AHA)/American College of Cardiology (ACC) guidelines ${ }^{58-}$ 61 recommend molecular testing to improve the diagnosis and management of patients and at-risk family members.

By these considerations, in 2013 the new cardiomyopathy classification system $\operatorname{MOGE}(\mathrm{S})^{32,62,63}$ has become necessary. MOGE(S) can assist in the diagnosis and management of each cardiomyopathy patient, classified following five attributes: Morpho-functional characteristic (M); Organ involvement (O); Genetic or familial inheritance pattern $(\mathrm{G})$; Etiological description (E) of genetic defect or nongenetic underlying cause; and functional Status (S), using the ACC/AHA stage (A to D) and the New York Heart Association (I to IV) functional classes. The " $\mathrm{S}$ " notation is especially useful when mutation carriers are healthy, or if they demonstrate imaging-verified early abnormalities suggestive of cardiomyopathy.

\section{Cardiac channelopathies}

Cardiac channelopathies are rare inherited primary electrical disorders, without evidence of structural cardiomyopathy, resulting from dysfunction of cardiac ion channels. This alteration impairs cardiac action potential or intracellular calcium handling and results in electrical instability ${ }^{50}$ leading to life-threatening cardiac arrhythmias, including ventricular tachycardia or fibrillation (VT/VF) predisposing to SCD. Channelopathies are usually transmitted as an autosomal dominant trait and show variable clinical penetrance and expressivity. The main clinical features include syncope and SCD; however, most patients remain asymptomatic throughout life and symptoms may be triggered by physical activity (light, moderate and heavy), sexual activity, emotions and sleep. Early diagnosis of genetic carriers is warranted, being the SCD in apparently healthy young people the potential presenting symptom; therefore, genetic testing has been progressively introduced in clinical practice.

The most frequent inherited cardiac channelopathies are long QT syndrome (LQTS), Brugada syndrome (BrS), and catecholaminergic polymorphic ventricular tachycardia (CPVT). Other rare inherited arrhythmogenic diseases are short QT syndrome (SQTS), sick sinus syndrome (SSS), familial progressive cardiac conduction defect (PCCD), Haïssaguerre syndrome or early repolarization syndrome..$^{47-49}$ To date, more than 40 genes are implicated in cardiac channelopathies $^{47,64}$ (Appendix Table 1): the most common genes encode the cardiac sodium and potassium voltage-gated channels $\left(\mathrm{Na}_{\mathrm{V}} 1.5, \mathrm{~K}_{\mathrm{V}} 7.1\right.$ and $\left.\mathrm{K}_{\mathrm{V}} 11.1\right)$, the L-type calcium channel $\left(\mathrm{Ca}_{\mathrm{V}} 1.2\right)$, the cardiac receptor of ryanodine (RyR2). Mutations in these genes may cause loss or gain of channel function, although mixed effects on ion channels are also reported. ${ }^{65-67}$

LQTS is a cardiac channelopathy, characterized by abnormally prolonged QT interval. ${ }^{68-71}$ To the best of our knowledge, pathogenic variants associated with LQTS have been identified in the following genes: AKAP9, ANK2, CACNA1C, CALM1, CALM2, CALM3, CAV3, KCNE2, KCNH2, KCNJ2, KCNJ5, RYR2, SCN1B, SCN4B, SCN5A and SNTA1, showing an autosomaldominant inheritance; TRDN, resulting in an autosomal-recessive pattern, and KCNQ1 and KCNE1 with both autosomaldominant and -recessive hereditary ${ }^{72}$ (Appendix Table 1). In particular, the three major LQTS-susceptibility genes are $K C N Q 1, K C N H 2$ and SCN5A, encoding the $\alpha$-subunit of the voltage-dependent $\mathrm{K}_{\mathrm{V}} 7.1$, 
$\mathrm{K}_{\mathrm{V}} 11.1$ and $\mathrm{Na}_{\mathrm{v}} 1.5$ channels, respectively. ${ }^{73-}$

${ }^{75}$ Generally, gain of function mutations of sodium channel or loss of function mutations of potassium channels prolong cardiac action potential, producing a prolonged repolarization in cardiac cells and prolonged QT interval on the ECG. These three genes, together, explain up to $75 \%$ of LQTS clinical diagnosed patients, while the remaining genes contribute up to an additional $5-10 \%$ of LQTS cases. ${ }^{72,76,77}$ Of note, subjects carrying mutations in KCNQ1 gene are at high risk to develop VT/VF during physical activity.

About $20-25 \%$ of Brugada patients carry loss of function mutations in the SCN5A gene. In addition, CACNAIC, SCN10A, CACNB2, ABCC9 genes, among about 30 other associated genes, are each responsible for just over $5 \%$ of positivegenotype patients, while the remaining genes are very rare ${ }^{72,78,79}$ (Appendix Table 1). Overall, known susceptibility BrS genes explain about $40 \%$ of cases, indicating that about $60 \%$ of $\mathrm{BrS}$ patients remain genetically unresolved. Furthermore, genomewide association studies (GWAS) have demonstrated that common genetic variants increase susceptibility to Brugada syndrome, suggesting a polygenic way of inheritance, also. ${ }^{80}$

Physical activity, increasing parasympathetic tone and body temperatures, may precipitate fatal arrhythmias in BrS asymptomatic subjects.

CPVT is a rare channelopathy with both autosomal-dominant and, less commonly, autosomal-recessive inheritance, ${ }^{81,82}$ showing polymorphic ventricular tachyarrhythmia, which can lead to syncope or SCD under physical stress or emotional conditions. Clinical symptoms and higher risk of cardiac events occur in youth particularly in males. ${ }^{83,84}$ CPVT is, generally, caused by gain of function mutations in RYR2 gene, coding the ionic channel for the release of calcium from the sarcoplasmic reticulum, which plays a crucial role in regulating intracellular calcium concentrations. RYR2 gene is mutated in about $60 \%$ of CPTV patients, while only a small percentage of subjects carry mutations in other genes (Appendix Table 1). ${ }^{85-88}$

SQTS is a very rare cardiac channelopathy, characterized by peculiarly short QT intervals and increased susceptibility to develop atrial and ventricular tachyarrhythmia, which may arise later on physical activity. ${ }^{89}$ The main symptom is the cardiac arrest (up to $40 \%$ ). ${ }^{90}$ Mutations (generally of the gain of function type) in $K C N Q 1$, KCNH2, KCNJ2, CACNA1C, CACNB2, $C A C N A 2 D 1$, SCN5A and SLC4A3 genes are involved in disease (Table 1), although the diagnostic sensibility of genetic test for SQTS is low (15-25\%). . $^{89,91-93}$

Globally, the diagnostic sensibility of genetic test for channelopathies is variable, ranging from $70-85 \%$ in LQTS to $15-25 \%$ in SQTS; therefore, genetic screening in genes known to cause cardiac channelopathies might result unsuccessful in around $15-30 \%$ of patients with LQTS, $40 \%$ of patients with CPVT, and $60-85 \%$ of patients with BrS or SQTS.

In the last decade it has become evident that hereditary channelopathies can also be caused by mutations in genes encoding cardiac ion channels regulatory proteins, such as transcription factors and proteins involved in the expression, intracellular transport and subsequent subcellular localizations of ion channels. ${ }^{94}$ For example, pathogenic variants in Calsequestrin (CASQ2), encoding the calsequestrin 2 protein, and calmodulin genes (CALM1, CALM2 and CALM3) are involved in the intracellular calcium homeostasis and are associated with LQTS and/or CPVT. ${ }^{95-98}$ Of note, $C A S Q 2$ mutations trigger SCD with a frequency higher than $R Y R 2$ mutations. ${ }^{99}$ Mutations in genes encoding other ionchannel associated proteins, such as caveolin (CAV3), ankyrins ( $A N K 3, A N K 2)$, syntrophin (SNTA1), and yotiao (AKAP-9) are now implicated in the genesis of the cardiac channelopathies, although they affect only a very small proportion of arrhythmic patients. ${ }^{94,100-107}$

\section{Arrhythmogenic ventricular car- diomyopathy}

Arrhythmogenic ventricular cardiomyopathy is an inherited heart muscle disease, showing typically ECG abnormalities and ventricular arrhythmias. ${ }^{108}$

$\mathrm{ACM}$ is characterized by a progressive loss of myocytes and fibro-fatty replacement; biventricular involvement is often observed in later stages.

ACM is reported to cause $0,08-3,6 \%$ of SCDs/year; ${ }^{109}$ however patients with known genotype are characterized by mortality $<1 \%$, as reported in recent literature. ${ }^{110}$

Mutations in desmosomal genes are found in about $50-60 \%$ of ACM patients, defining desmosomes as major factors in ACM pathogenesis. ${ }^{111-113}$ Desmosomes are intercellular junctions that provide strong adhesion between cells and link, intracellularly, to the intermediate cytoskeleton filament. They are found in tissue that experience intense mechanical stress, such as cardiac muscle tissue and epidermis. The linkage between the intermediate filaments and the desmosomal adhesion molecules is mediated by desmoplakin and the armadillo proteins plakoglobin and plakophilin. Thus, desmosomes contain desmoplakin, plakoglobin and at least one isoform each of plakophilin and the desmosomal cadherins desmocollin and desmoglein. A number of other accessory proteins are associated with desmosomes. Desmosomal genes related to ACM (Appendix Table 1) include $P K P 2$, $D S G 2, D S C 2, J U P$ and $D S P$, encoding plakophilin-2, desmoglein, desmocollin, plakoglobin, desmoplakin, respectively. PKP2 is the most frequently mutated gene in ACM patients, associated with about 30$40 \%$ of cases. ${ }^{114,115}$ Plakophilins exhibit dual localization, in the desmosomes as well as in the nucleus, where they can trigger fibroadipocytic replacement of cardiac myocytes by suppression of Wnt/betacatenin pathway. ${ }^{116}$

Of note, mutations in desmosomal genes are founded in about 5\% of DCM cases, suggesting that there are little differences, in some cases, between ACM and DCM. ${ }^{108,117}$

Mutations in $\alpha \mathrm{T}$-catenin $(C T N N A 3)$ and $\mathrm{N}$-cadherin $(\mathrm{CDH} 2)$ are also associated with ACM. ${ }^{118,119}$ Both proteins are present in the area composita at the cardiac intercalated discs. Alpha-T-catenin binds plakophilins contributing to the formation of the area composita, which strengthens cell-cell adhesion in contractile cardiomyocytes. This involvement shows that the pathogenesis of ACM extends beyond desmosomes. Area composite is a mixedtype junctional structure composed of both desmosomal and adherents junctional proteins. Physiologically, important interactions exist between the cardiac desmosome and gap and adherents junctions, with the resulting integrity of the intercalated disc and its important role in both mechanical and electrical cellular stability dependent on adequate functioning of all three subunits.

Rare mutations in TMEM43, transmembrane protein 43 , located in nucleus inner membrane, are associated with severe ACM phenotypes, ${ }^{120}$ high penetrance and high SCD risk. ${ }^{111,121,122}$ This gene contains a response element for PPAR $\gamma$ (an adipogenic transcription factor), which may explain the fibrofatty replacement of the myocardium, a characteristic pathological finding in ACM. ${ }^{123}$

\section{Hypertrophic cardiomyopathy}

Hypertrophic Cardiomyopathy is a myocardial disease, characterized by thickening of the interventricular septum and left ventricular wall, in the absence of clinically 
important abnormal loading conditions or primary valve disease. The most specific histological features include myocyte hypertrophy and disarray, as well as interstitial fibrosis.

HCM is the most common cause of sudden death, ${ }^{25}$ particularly in adolescents and young adults, and the most common cause of SCD in athletes, in the United States. ${ }^{25,124}$ Nonsustained ventricular tachycardia, syncope, family history of sudden cardiac death, and severe cardiac hypertrophy are the major risk factors for sudden cardiac death. ${ }^{125}$ Furthermore, the presence of underlying but undiagnosed HCM in athletes is among the main causes of SCD, with the majority $(60 \%)$ of cases occurring during exercise. ${ }^{27}$

Hypertrophic Cardiomyopathy is a genetic disease, generally transmitted as autosomal dominant trait and characterized by marked genetic heterogeneity. ${ }^{61,126}$ Mutations in about 100 different genes have been described associated to HCM; however, mutations in eight sarcomeric genes are responsible for approximately $60-70 \%$ of cases of HMC. ${ }^{61,126}$ Typically, the most commonly genes involved in HCM are MYBPC3 (myosin-binding protein C3), MYH7 (myosin heavy chain 7), TNNT2 (cardiac troponin T), TNNI (cardiac troponin I), ACTC1 (actin alpha cardiac muscle 1), TPM1 (tropomyosin 1), MYL2 (myosin light chain 2), MYL3 (myosin light chain 3); other six sarcomeric genes are involved in less than $10 \%$ of cases $^{41,127,128}$ (Appendix Table 1). Most sarcomere mutations result in a single amino acid substitution, with the exception of mutations in the $M Y B P C 3$ gene, which are most frequently frameshift mutations, and create a premature-termination codon. Allelic balance between mutant and wild-type sarcomere proteins is variable and mutation-specific, reflecting differential stability or efficiency of sarcomere incorporation of mutated protein compared to the wild-type.

About $5 \%$ of HCM patients carry multiple sarcomeric mutations: these patients present with more severe disease at an earlier age. ${ }^{128-131}$ As a result, more extensive genetic evaluation may be warranted in probands presenting with early or severe disease.

More rarely (less than $1 \%$ of cases) $\mathrm{HCM}$ patients present mutations in genes encoding Z-disc or calcium-handling proteins. The sarcomeric Z-disc defines the lateral borders of the sarcomere and is important not only for mechanical stability and force transmission but also for signalling, mechanosensation, mechanotransduction, apoptosis and cell survival. It is composed of numerous proteins, such as titin, myopal- ladin, nebulette, obscurin, actinin, telethonin. However, mutations in Z-disc genes give rise to heterogenous diseases encompassing various cardiomyopathies such as DCM, HCM, ACM. ${ }^{132,133}$

Although the utilization of next-generation sequencing methods has increased the spectrum of the putative HCM related genes, recent studies have suggested that mutations in non sarcomeric genes are very rare cause of HCM. ${ }^{134,135}$

\section{Dilated cardiomyopathy}

Dilated cardiomyopathy, characterized by left ventricular enlargement and systolic dysfunction, is a heterogeneous heart disease leading to progressive systolic heart failure and sudden cardiac death. When DCM occurs, in the absence of an identifiable cause, the disease is referred to as idiopathic DCM (IDCM). Familial DCM (FDCM) demonstrates marked genetic heterogeneity and age-dependent penetrance, with disease developing in childhood, adolescence and middle age, but rarely in the elderly. More than 40 genes have been identified in association with non-syndromic FDCM, the majority demonstrating autosomal dominant inheritance. ${ }^{136}$ They encode cytoskeletal, sarcomeric, nuclear proteins and act through different pathogenetic mechanisms, such as disruption of sarcomere-cytoskeletal interactions or myocyte architecture; amyloid deposition; abnormalities of desmosomal, calcium handling, ion channel function; alterations of mitochondrial energy dynamics or nuclear membrane-cytoskeletal integrity.

TTN gene, encoding the titin protein, is the most frequently mutated gene in DCM patients (up to $25 \%$ of cases, Appendix Table 1). ${ }^{137,138}$ Titin is an elastic protein, which passively stretched during the diastole and then returns to its initial state. However, it is also a biomolecular scaffold and mediates multiple protein interactions and intracellular signalling cascades, which may exert regulatory functions on muscular activity. The TTN mutations are generally nonsense, splice variants or deletion/insertions mutations, producing a truncated protein. Also mutations in genes encoding for sarcomeric thin and thick filaments (MYPBC3, MYH7, TNNT2, TNNI3, ACTC1, TPM1, MYL2, MYL3), ${ }^{32,139}$ and other proteins interacting with titin [myomesin 1 (MYOM1), cardiac ankyrin repeat protein 1 (ANKRD1) and telethonin (TCAP)] have been found in up to $5-10 \%$ of DCM patients ${ }^{137,140-144}$ indicating that a complex network of proteins organized around the central scaffold titin may be defective in
DCM. ${ }^{145}$ About $10 \%$ of DCM patients, ${ }^{146,147}$ show mutations in LMNA gene. ${ }^{148}$ Lamins A and $\mathrm{C}$ are intermediate filament nuclear envelope proteins, encoded by the LMNA gene, implicated in DNA replication, cellcycle regulation, chromatin organization, differentiation maintenance, nuclear stability, pore positioning, gene expression and signal transduction. Through alternative splicing, a single transcript generates four products, collectively known as lamin $\mathrm{A} / \mathrm{C}$. Lamin A/C is associated with the LInker of Nucleoskeleton and Cytoskeleton (LINC) bridge complex, which links the nucleus to the actin cytoskeleton. The major components of the LINC complex are: lamin A/C (LMNA), emerin (EMD), nesprins-1 (SYNE1) and nesprins-2 (SYNE-2) and SUNdomain containing proteins $(S U N 1 / 2) .{ }^{146}$ Mutations in all these genes are involved in DCM as well as in rare cases of ACM. ${ }^{148-151}$

Other cytoskeletal proteins involved in DCM are desmin (DES), dystrophin $(D M D)$, alpha-dystroglycan (DAG1), dystrobrevin (DTNA), sarcoglycan (SGCD), syntrophin (SNTA1), phospholamban $(P L N)$, caveolin (CAV3).

Desminopathy is one of the most common intermediate filament human disorders associated with mutations in desmin and alphaB-crystallin proteins. Desmin links desmosomes with the $\mathrm{Z}$ disk, helping to connect myofibrils together. This allows the formation of a continuous cytoskeletal network that maintains a spatial relationship between the contractile apparatus and other structural elements of the cell, providing maintenance of cellular integrity, force transmission and mechanochemical signaling. Desminopathy-associated diseases may be associated with DCM, ACM ${ }^{151,152}$ and restrictive cardiomyopathy. ${ }^{153}$

Among the rare DCM genes, SCN5A, FLNC and $P L N$ genes, deserve particular attention. FLNC codes the Filamin C protein, an actin cross-linking molecule, which contributes to the sarcomeric architecture; PLN gene encodes phospholamban protein, a key regulator of the sarcoplasmic reticulum $\mathrm{Ca}^{2+}$ ATPase pump (SERCA2a), which, in turn, is responsible for the calcium homeostasis. ${ }^{154-156}$

DCM patients carrying mutations in SCN5A, FLNC or PLN genes, as well as in $L M N A$, had a prominent arrhythmogenic phenotype and a higher risk for life-threatening ventricular arrhythmias and SCD. Therefore, early identification of patients carrying mutations in these genes is particular imperative. ${ }^{108}$

The great genetic heterogeneity associated to DCM demonstrates a central relevance for cytoskeletal integrity and biomechanical coupling of elastic and contractile 
elements. Mutations in cytoskeletal proteins critically diminish force generation and interfere with mechanical transduction within the contractile apparatus of the myocardium, thereby ultimately leading to impaired systolic function. ${ }^{157}$ In addition, cytoskeletal alterations can affect ion channel anchoring and trafficking, causing an imbalance in cardiac ionic homeostasis with subsequent action potential and conduction alterations that will trigger arrhythmogenesis. ${ }^{158,159}$

\section{High-throughput sequencing technology: Next Generation Sequencing (NGS)}

The correct molecular diagnostic framework of inherited cardiomyopathies is often very complex, because of high clinical and genetic heterogeneity (Figure 1). ${ }^{160}$

The sequencing with the traditional techniques such as Sanger sequencing of a lot number of genes requires long execution times and involves a lower diagnostic and analytical sensitivity. These limitations have been overcome by the development of highly productive nucleic acid sequencing techniques ("Next Generation Sequencing", NGS). ${ }^{161}$ These methods allow the analysis of a large number of nucleotides, from a single exon or gene, up to the analysis of gene panels, or of the whole exome or genome, ${ }^{127,162}$ accurately and at extremely competitive costs compared to traditional methods.

The analysis of gene panels by NGS sequencing represents the ideal analytical approach to identify DNA mutations associated with genetically heterogeneous pathologies, such as cardiomyopathies and channelopathies. This approach not only allows to analyze a large number of genes simultaneously in several patients, but, through the identification of further variants associated with the disease phenotype, allows to obtain information also on possible additional genetic factors that can act as phenotype modifiers or predict the patient's prognosis. Recent evidence supports the importance of a sensible molecular analysis also in athletes showing a reasonable index of suspicion for an inherited cardiomyopathy or channelopathy, in order to early identify or prevent serious complications, up to the risk of sudden death. ${ }^{54,163,164}$ The use of genetic test by NGS methodologies could be taken as a useful implementation in the path of cardiological prevention for athletes, when the pre-participation screening shows a family history of SCD, cardiomyopathy/channelopathy or, symptoms and/or instrumental signs, even borderline, of cardiac dysfunction. The integrated diagnostic path may result in an exhaustive precise characterization of the underlying cardiac inherited disease.

\section{Conclusions}

Subjects practicing routine sports, both at a competitive and amateur level, have a lifestyle characterized by a vigorous and continuous physical effort. However, sudden cardiac death, often due

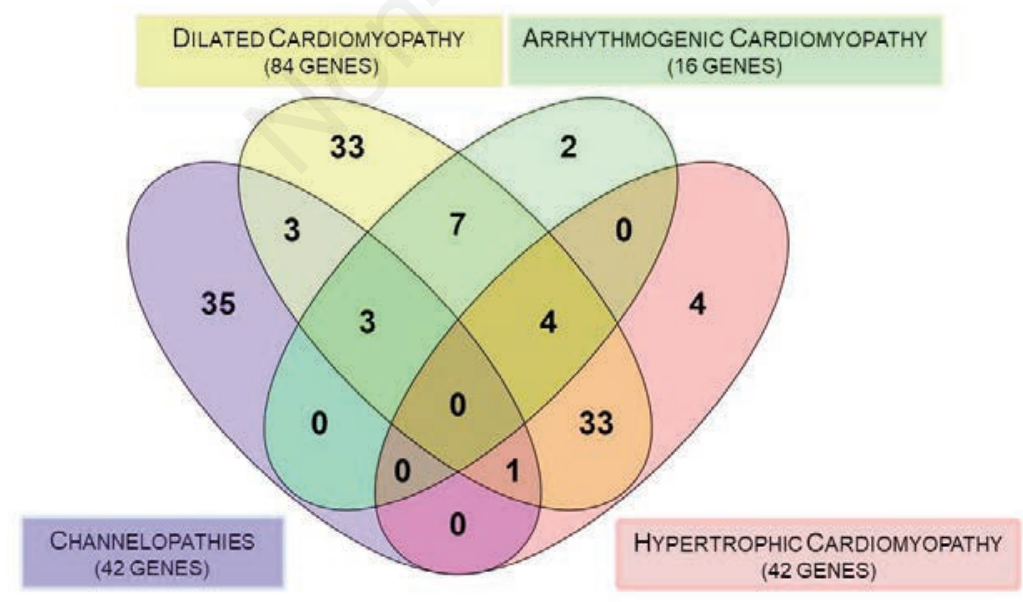

Figure 1. Schematic representation of cardiomyopathies and genes involved in Sudden Cardiac Death, can reflect our work and be used as a cover image. Diagram shows the overlap between the genes associated with Channelopathies, Dilated Cardiomyopathy (DCM), Hypertrophic Cardiomyopathy (HCM), Arrhythmogenic Cardiomyopathy (ACM).

to hidden cardiovascular disease, can suddenly affect even high-value athletes. SCD related to the practice of sports accounts for about $6 \%$ of the total $\mathrm{SCDs}^{17}$, both in competitive and amateur young athletes. ${ }^{25}$ In fact, athletes, also asymptomatic, may be at risk of SCD while they're training or competing, due to cardiovascular defects they may not even be aware of. To date, pre-participation cardiovascular screening of athletes is a lifesaving and cost-effective strategy in athletes in whom SCD can be caused by heart muscle diseases and is recommended by both the AHA and ESC. The AHA recommends screening competitive athletes by means of family/personal history and physical examination. ${ }^{165}$ In Italy, a mandatory state-sponsored screening program exists for all competitive athletes, including symptoms evaluation, family history, physical examination and 12-lead ECG. This protocol was acknowledged by the ESC to propose for a common European conduct. ${ }^{166}$

A recent study by the Institute of Sports Medicine of Italian National Olympic Committee (CONI), conducted on more than 2,300 athletes who had taken part in the Olympic Games from 2004 (Athens) to 2014 (Sochi), confirms the opportunity to subject athletes to pre-participation cardiovascular screening and other examinations when necessary. ${ }^{167}$ About $0,2 \%$ of these athletes were found to have inherited cardiomyopathies, and globally about $4 \%$ showed cardiovascular abnormalities (coronary heart disease, high blood pressure, heart rhythm disorders) all equally asymptomatic.

The main aim of this review is to provide genetic support to prevent sudden cardiac death in young athletes, a highly visible tragedy that generates significant media attention and discussion among medical personnel, sports communities and laypersons alike. We think that genetic cardiomyopathy testing in athletes may be an integrative tool to reach a definitive diagnosis when the pre-participation screening shows personal symptoms (i.e. syncope, arrhythmias) or instrumental signs of heart dysfunction, even borderline, suggesting the presence of an inherited cardiomyopathy/ channelopathy. ${ }^{168}$ Moreover, the genetic test may also be indicated in athletes with a family history of SCD or when a his/her family member is affected by cardiomyopathy/channelopathy and carries a disease-causing mutation. In this setting, the identification of athletes carrying a pathogenic mutation allows to detect individuals at risk in the pre-clinical or asymptomatic phase. 


\section{References}

1. Karlsen T, Aamot IL, Haykowsky M, Rognmo O. High Intensity Interval Training for Maximizing Health Outcomes. Prog Cardiovasc Dis. 2017;60:67-77.

2. Piepoli MF, Hoes AW, Agewall S, et al. 2016 European Guidelines on cardiovascular disease prevention in clinical practice: The Sixth Joint Task Force of the European Society of Cardiology and Other Societies on Cardiovascular Disease Prevention in Clinical Practice (constituted by representatives of 10 societies and by invited experts)Developed with the special contribution of the European Association for Cardiovascular Prevention \& Rehabilitation (EACPR). Eur Heart J. 2016;37:2315-81.

3. Scudiero O, Pero R, Ranieri A, et al. Childhood obesity: an overview of laboratory medicine, exercise and microbiome. Clin Chem Lab Med. 2019.

4. Harber MP, Kaminsky LA, Arena R, et al. Impact of Cardiorespiratory Fitness on All-Cause and Disease-Specific Mortality: Advances Since 2009. Prog Cardiovasc Dis. 2017;60:11-20.

5. Lee DC, Brellenthin AG, Thompson PD, Sui X, Lee IM, Lavie CJ. Running as a Key Lifestyle Medicine for Longevity. Prog Cardiovasc Dis. 2017;60:45-55.

6. Lee DC, Pate RR, Lavie CJ, Sui X, Church TS, Blair SN. Leisure-time running reduces all-cause and cardiovascular mortality risk. J Am Coll Cardiol. 2014;64:472-81.

7. De Ferrari GM, Dusi V, Ruffinazzi M, et al. Risk factors for primary ventricular fibrillation during a first myocardial infarction: Clinical findings from PREDESTINATION (PRimary vEntricular fibrillation and suDden dEath during firST myocardIal iNfArcTION). Int J Cardiol. 2020;302:164-70.

8. De Ferrari GM, Dusi V, Ruffinazzi M, et al. Physical Inactivity Is a Risk Factor for Primary Ventricular Fibrillation. J Am Coll Cardiol. 2019;73:2117-8.

9. Williams MA, Haskell WL, Ades PA, et al. Resistance exercise in individuals with and without cardiovascular disease: 2007 update - A scientific statement from the American Heart Association Council on Clinical Cardiology and Council on Nutrition, Physical Activity, and Metabolism. Circulation. 2007;116:572-84.

10. Adams V, Reich B, Uhlemann M, Niebauer J. Molecular effects of exer- cise training in patients with cardiovascular disease: focus on skeletal muscle, endothelium, and myocardium. Am J Physiol Heart Circ Physiol. 2017;313: H72-H88.

11. Lombardo B, Izzo V, Terracciano D, et al. Laboratory medicine: health evaluation in elite athletes. Clin Chem Lab Med. 2019;57:1450-73.

12. Finocchiaro G, Sharma S. The Safety of Exercise in Individuals With Cardiomyopathy. Can J Cardiol. 2016; 32:467-74.

13. Corrado D, Basso C, Rizzoli G, Schiavon M, Thiene G. Does sports activity enhance the risk of sudden death in adolescents and young adults? J Am Coll Cardiol. 2003;42:1959-63.

14. Finocchiaro G, Papadakis M, Robertus JL, et al. Etiology of Sudden Death in Sports: Insights From a United Kingdom Regional Registry. J Am Coll Cardiol. 2016;67:2108-15.

15. Maron BJ, Haas TS, Ahluwalia A, Murphy CJ, Garberich RF. Demographics and Epidemiology of Sudden Deaths in Young Competitive Athletes: From the United States National Registry. Am J Med. 2016;129:1170-7.

16. Marijon E, Uy-Evanado A, Reinier K, et al. Response to Letter Regarding Article, "Sudden Cardiac Arrest During Sports Activity in Middle Age". Circulation. 2015;132:e356.

17. Berdowski J, de Beus MF, Blom M, et al. Exercise-related out-of-hospital cardiac arrest in the general population: incidence and prognosis. Eur Heart J. 2013;34:3616-23.

18. Asif IM, Harmon KG. Incidence and Etiology of Sudden Cardiac Death: New Updates for Athletic Departments. Sports Health. 2017;9: 268-79.

19. Wasfy MM, Hutter AM, Weiner RB. Sudden Cardiac Death in Athletes. Methodist Debakey Cardiovasc J. 2016;12:76-80.

20. Marijon E, Tafflet M, Celermajer DS, et al. Sports-related sudden death in the general population. Circulation. 2011;124:672-81.

21. Mazzaccara C, D'Argenio V, Nunziato M, Esposito MV, Salvatore F, Frisso G. Clinical molecular biology in the assessment and prevention of cardiological risk in case of participation in sports activity and intense physical activity. Biochimica Clinica. 2019;43: 24-43.

22. Priori SG, Blomstrom-Lundqvist C, Mazzanti A, et al. 2015 ESC Guidelines for the management of patients with ventricular arrhythmias and the prevention of sudden cardiac death: The Task Force for the Management of Patients with Ventricular Arrhythmias and the Prevention of Sudden Cardiac Death of the European Society of Cardiology (ESC). Endorsed by: Association for European Paediatric and Congenital Cardiology (AEPC). Eur Heart J. 2015;36:2793-867.

23. Quenin P, Kyndt F, Mabo P, et al. Clinical Yield of Familial Screening After Sudden Death in Young Subjects: The French Experience. Circ Arrhythm Electrophysiol. 2017;10.

24. Barletta V, Fabiani I, Lorenzo C, Nicastro I, Bello VD. Sudden Cardiac Death: A Review Focused on Cardiovascular Imaging. J Cardiovasc Echogr. 2014;24:41-51.

25. Zorzi A, Pelliccia A, Corrado D. Inherited cardiomyopathies and sports participation. Neth Heart J. 2018;26: 154-65.

26. Asif IM, Yim ES, Hoffman JM, Froelicher V. Update: Causes and symptoms of sudden cardiac death in young athletes. Phys Sportsmed. 2015; 43:44-53.

27. Harmon KG, Asif IM, Maleszewski JJ, et al. Incidence, Cause, and Comparative Frequency of Sudden Cardiac Death in National Collegiate Athletic Association Athletes: A Decade in Review. Circulation. 2015; 132:10-9.

28. Holst AG, Winkel BG, Theilade J, et al. Incidence and etiology of sports-related sudden cardiac death in Denmarkimplications for preparticipation screening. Heart Rhythm. 2010;7: 1365-71.

29. Margey R, Roy A, Tobin S, et al. Sudden cardiac death in 14- to 35-year olds in Ireland from 2005 to 2007: a retrospective registry. Europace. 2011; 13:1411-8.

30. Suarez-Mier MP, Aguilera B, Mosquera RM, Sanchez-de-Leon MS. Pathology of sudden death during recreational sports in Spain. Forensic Sci Int. 2013;226:188-96.

31. de Noronha SV, Behr ER, Papadakis $\mathrm{M}$, et al. The importance of specialist cardiac histopathological examination in the investigation of young sudden cardiac deaths. Europace. 2014;16: 899-907.

32. Arbustini E, Narula N, Tavazzi L, et al. The MOGE(S) classification of cardiomyopathy for clinicians. J Am Coll Cardiol. 2014;64:304-18.

33. Van Camp SP, Bloor CM, Mueller FO, 
Cantu RC, Olson HG. Nontraumatic sports death in high school and college athletes. Med Sci Sports Exerc. 1995; 27:641-7.

34. Maron BJ, Doerer JJ, Haas TS, Tierney DM, Mueller FO. Sudden deaths in young competitive athletes: analysis of 1866 deaths in the United States, 19802006. Circulation. 2009;119:1085-92.

35. Emery MS, Kovacs RJ. Sudden Cardiac Death in Athletes. Jacc-Heart Failure. 2018;6:30-40.

36. Chandra N, Bastiaenen R, Papadakis M, Sharma S. Sudden cardiac death in young athletes: practical challenges and diagnostic dilemmas. J Am Coll Cardiol. 2013;61:1027-40.

37. Skinner JR, Winbo A, Abrams D, Vohra J, Wilde AA. Channelopathies That Lead to Sudden Cardiac Death: Clinical and Genetic Aspects. Heart Lung Circ. 2019;28:22-30.

38. Corrado D, Zorzi A. Sudden death in athletes. Int J Cardiol. 2017;237:67-70.

39. Jacoby D, McKenna WJ. Genetics of inherited cardiomyopathy. Eur Heart J. 2012;33:296-304

40. Watkins H, Ashrafian H, Redwood C. Inherited cardiomyopathies. $\mathrm{N}$ Engl J Med. 2011;364:1643-56.

41. Maron BJ, Maron MS, Semsarian C. Genetics of hypertrophic cardiomyopathy after 20 years: clinical perspectives. J Am Coll Cardiol. 2012;60:70515.

42. Norton N, Li D, Rampersaud E, et al. Exome sequencing and genome-wide linkage analysis in 17 families illustrate the complex contribution of TTN truncating variants to dilated cardiomyopathy. Circ Cardiovasc Genet. 2013;6:144-53.

43. Hershberger RE, Siegfried JD. Update 2011: clinical and genetic issues in familial dilated cardiomyopathy. J Am Coll Cardiol. 2011;57:1641-9.

44. Jarcho JA, McKenna W, Pare JA, et al. Mapping a gene for familial hypertrophic cardiomyopathy to chromosome 14q1. N Engl J Med. 1989;321: 1372-8.

45. Meder B, Ruhle F, Weis T, et al. A genome-wide association study identifies 6 p21 as novel risk locus for dilated cardiomyopathy. Eur Heart J. 2014;35: 1069-77.

46. Villard E, Perret C, Gary F, et al. A genome-wide association study identifies two loci associated with heart failure due to dilated cardiomyopathy. Eur Heart J. 2011;32:1065-76.

47. Wilde AAM, Amin A. Channelopathies, genetic testing and risk stratification. Int J Cardiol. 2017;
237:53-5.

48. Mazzanti A, Underwood K, Nevelev D, Kofman S, Priori SG. The new kids on the block of arrhythmogenic disorders: Short QT syndrome and early repolarization. J Cardiovasc Electrophysiol. 2017;28:1226-36.

49. Detta N, Frisso G, Limongelli G, Marzullo M, Calabro R, Salvatore F. Genetic analysis in a family affected by sick sinus syndrome may reduce the sudden death risk in a young aspiring competitive athlete. Int $\mathrm{J}$ Cardiol. 2014; 170:e63-5.

50. Garcia-Elias A, Benito B. Ion Channel Disorders and Sudden Cardiac Death. Int J Mol Sci. 2018;19.

51. Detta N, Frisso G, Salvatore F. The multi-faceted aspects of the complex cardiac Nav1.5 protein in membrane function and pathophysiology. Biochim Biophys Acta. 2015;1854: 1502-9.

52. Detta N, Frisso G, Zullo A, et al. Novel deletion mutation in the cardiac sodium channel inactivation gate causes long QT syndrome. Int $\mathrm{J}$ Cardiol. 2013;165:362-5.

53. McKenna WJ, Maron BJ, Thiene G. Classification, Epidemiology, and Global Burden of Cardiomyopathies. Circ Res. 2017;121:722-30.

54. Mazzaccara C, Redi A, Lemme E, Pelliccia A, Salvatore F, Frisso G. Impact of molecular diagnostics in an asymptomatic amateur athlete found to be affected by hypertrophic cardiomyopathy. Medicina Dello Sport. 2018;71:405-12.

55. Olivotto I, Kassem HS, Girolami F. Genetic testing for hypertrophic cardiomyopathy: ongoing voyage from exploration to clinical exploitation. Cardiogenetics. 2011;1:3.

56. Frisso G, Detta N, Coppola P, et al. Functional Studies and In Silico Analyses to Evaluate Non-Coding Variants in Inherited Cardiomyopathies. Int J Mol Sci. 2016;17.

57. Pricolo MR, Herrero-Galan E, Mazzaccara C, Losi MA, AlegreCebollada J, Frisso G. Protein Thermodynamic Destabilization in the Assessment of Pathogenicity of a Variant of Uncertain Significance in Cardiac Myosin Binding Protein C. J Cardiovasc Transl Res. 2020.

58. Gersh BJ, Maron BJ, Bonow RO, et al. 2011 ACCF/AHA guideline for the diagnosis and treatment of hypertrophic cardiomyopathy: a report of the American College of Cardiology Foundation/American Heart Association Task Force on Practice
Guidelines. Circulation. 2011;124: e783-831.

59. Authors/Task Force m, Elliott PM, Anastasakis A, et al. 2014 ESC Guidelines on diagnosis and management of hypertrophic cardiomyopathy: the Task Force for the Diagnosis and Management of Hypertrophic Cardiomyopathy of the European Society of Cardiology (ESC). Eur Heart J. 2014;35:2733-79.

60. Charron P, Arad M, Arbustini E, et al. Genetic counselling and testing in cardiomyopathies: a position statement of the European Society of Cardiology Working Group on Myocardial and Pericardial Diseases. Eur Heart J. 2010;31:2715-26.

61. Elliott PM, Anastasakis A, Borger MA, et al. 2014 ESC Guidelines on diagnosis and management of hypertrophic cardiomyopathy: the Task Force for the Diagnosis and Management of Hypertrophic Cardiomyopathy of the European Society of Cardiology (ESC). Eur Heart J. 2014;35:2733-79.

62. Arbustini E, Narula N, Dec GW, et al. The MOGE(S) Classification for a Phenotype-Genotype Nomenclature of Cardiomyopathy: Endorsed by the World Heart Federation. Glob Heart. 2013;8:355-82.

63. Westphal JG, Rigopoulos AG, Bakogiannis $\mathrm{C}$, et al. The MOGE(S) classification for cardiomyopathies: current status and future outlook. Heart Fail Rev. 2017;22:743-52.

64. Lee HH, Ching CK. Practical Aspects in Genetic Testing for Cardiomyopathies and Channelopathies. Clin Biochem Rev. 2019;40:187-200.

65. Zullo A, Frisso G, Detta N, et al. Allelic Complexity in Long QT Syndrome: A Family-Case Study. Int J Mol Sci. 2017;18.

66. Makita N, Behr E, Shimizu W, et al. The E1784K mutation in SCN5A is associated with mixed clinical phenotype of type 3 long QT syndrome. Journal of Clinical Investigation. 2008;118:2219-29.

67. Detta N, Frisso G, Zullo A, et al. Novel deletion mutation in the cardiac sodium channel inactivation gate causes long QT syndrome. Int J Cardiol. 2013;165:362-5.

68. Medeiros-Domingo A, Iturralde-Torres P, Ackerman MJ. Clinical and genetic characteristics of long QT syndrome. Revista Espanola De Cardiologia. 2007;60:739-52.

69. Roden DM. Long-QT syndrome. New England Journal of Medicine. 2008; 
358:169-76.

70. Morita H, Wu JS, Zipes DP. The QT syndromes: long and short. Lancet. 2008;372:750-63.

71. Sarubbi B, Frisso G, Romeo E, et al. Efficacy of pharmacological treatment and genetic characterization in early diagnosed patients affected by long QT syndrome with impaired AV conduction. Int J Cardiol. 2011;149:109-13.

72. Fernandez-Falgueras A, SarquellaBrugada G, Brugada J, Brugada R, Campuzano O. Cardiac Channelopathies and Sudden Death: Recent Clinical and Genetic Advances. Biology (Basel). 2017;6.

73. Bellocq C, van Ginneken AC, Bezzina $\mathrm{CR}$, et al. Mutation in the KCNQ1 gene leading to the short QT-interval syndrome. Circulation. 2004;109: 2394-7.

74. Magi S, Lariccia V, Maiolino M, Amoroso S, Gratteri S. Sudden cardiac death: focus on the genetics of channelopathies and cardiomyopathies. J Biomed Sci. 2017;24:56.

75. George AL, Jr. Molecular and genetic basis of sudden cardiac death. Journal of Clinical Investigation. 2013;123:7583.

76. Ackerman MJ, Priori SG, Willems S, et al. HRS/EHRA expert consensus statement on the state of genetic testing for the channelopathies and cardiomyopathies this document was developed as a partnership between the Heart Rhythm Society (HRS) and the European Heart Rhythm Association (EHRA). Heart Rhythm. 2011;8:130839.

77. Nakano Y, Shimizu W. Genetics of long-QT syndrome. J Hum Genet. 2016;61:51-5.

78. Romero J, Li DL, Avendano R, Diaz JC, Tung R, Di Biase L. Brugada Syndrome: Progress in Genetics, Risk Stratification and Management. Arrhythm Electrophysiol Rev. 2019;8: 19-27.

79. Juang JJ, Horie M. Genetics of Brugada syndrome. J Arrhythm. 2016; 32:418-25.

80. Bezzina CR, Barc J, Mizusawa Y, et al. Common variants at SCN5A-SCN10A and HEY2 are associated with Brugada syndrome, a rare disease with high risk of sudden cardiac death (vol 45, pg 1044, 2013). Nature Genetics. 2013;45:1409-

81. Lieve KV, van der Werf C, Wilde AA. Catecholaminergic Polymorphic Ventricular Tachycardia. Circ J. 2016;80:1285-91.

82. Napolitano C, Priori SG. Diagnosis and treatment of catecholaminergic polymorphic ventricular tachycardia. Heart Rhythm. 2007;4:675-8.

83. Lehnart SE, Wehrens XH, Laitinen PJ, et al. Sudden death in familial polymorphic ventricular tachycardia associated with calcium release channel (ryanodine receptor) leak. Circulation. 2004;109:3208-14.

84. Priori SG, Napolitano C, Memmi M, et al. Clinical and molecular characterization of patients with catecholaminergic polymorphic ventricular tachycardia. Circulation. 2002;106:69-74.

85. Roston TM, Yuchi Z, Kannankeril PJ, et al. The clinical and genetic spectrum of catecholaminergic polymorphic ventricular tachycardia: findings from an international multicentre registry. Europace. 2018;20:541-7.

86. Sumitomo N. Current topics in catecholaminergic polymorphic ventricular tachycardia. J Arrhythm. 2016;32:34451.

87. Mizusawa Y. Recent advances in genetic testing and counseling for inherited arrhythmias. J Arrhythm. 2016;32:389-97.

88. Velcea AE, Siliste C, Vinereanu D. Catecholaminergic Polymorphic Ventricular Tachycardia - Looking to the Future. Maedica (Buchar). 2017;12:306-10.

89. Giustetto C, Di Monte F, Wolpert C, et al. Short QT syndrome: clinical findings and diagnostic-therapeutic implications. Eur Heart J. 2006;27:2440-7.

90. Mazzanti A, O'Rourke S, Ng K, et al. The usual suspects in sudden cardiac death of the young: a focus on inherited arrhythmogenic diseases. Expert Rev Cardiovasc Ther. 2014;12:499519.

91. Rudic B, Schimpf R, Borggrefe M. Short QT Syndrome - Review of Diagnosis and Treatment. Arrhythm Electrophysiol Rev. 2014;3:76-9.

92. Gollob MH, Redpath CJ, Roberts JD. The short QT syndrome: proposed diagnostic criteria. J Am Coll Cardiol. 2011;57:802-12.

93. Campuzano O, Sarquella-Brugada G, Cesar S, Arbelo E, Brugada J, Brugada R. Recent Advances in Short QT Syndrome. Front Cardiovasc Med. 2018;5:149.

94. Ackerman MJ, Mohler PJ. Defining a New Paradigm for Human Arrhythmia Syndromes Phenotypic Manifestations of Gene Mutations in Ion Channel- and Transporter-Associated Proteins. Circulation Research. 2010;107:45765.

95. Nyegaard M, Overgaard MT,
Sondergaard MT, et al. Mutations in calmodulin cause ventricular tachycardia and sudden cardiac death. Am J Hum Genet. 2012;91:703-12.

96. Yin G, Hassan F, Haroun AR, et al. Arrhythmogenic calmodulin mutations disrupt intracellular cardiomyocyte $\mathrm{Ca} 2+$ regulation by distinct mechanisms. J Am Heart Assoc. 2014;3:e000996.

97. Crotti L, Johnson CN, Graf E, et al. Calmodulin Mutations Associated With Recurrent Cardiac Arrest in Infants. Circulation. 2013;127:1009-+.

98. Crotti L, Spazzolini C, Tester DJ, et al. Calmodulin mutations and life-threatening cardiac arrhythmias: insights from the International Calmodulinopathy Registry. Eur Heart J. 2019;40:2964-+.

99. Postma AV, Denjoy I, Hoorntje TM, et al. Absence of calsequestrin 2 causes severe forms of catecholaminergic polymorphic ventricular tachycardia. Circulation Research. 2002;91:e21-6.

100. Motloch LJ, Larbig R, Darabi T, et al. Long-QT syndrome-associated caveolin-3 mutations differentially regulate the hyperpolarization-activated cyclic nucleotide gated channel 4. Physiol Int. 2017;104:130-8.

101. Vatta M, Ackerman MJ, Ye B, et al. Mutant caveolin-3 induces persistent late sodium current and is associated with long-QT syndrome. Circulation. 2006;114:2104-12.

102. Wu G, Ai T, Kim JJ, et al. alpha-1-syntrophin mutation and the long-QT syndrome: a disease of sodium channel disruption. Circ Arrhythm Electrophysiol. 2008;1:193-201.

103. Marx SO, Marks AR. Regulation of the ryanodine receptor in heart failure. Basic Res Cardiol. 2002;97 Suppl 1:I49-51.

104. Hulme JT, Westenbroek RE, Scheuer T, Catterall WA. Phosphorylation of serine 1928 in the distal C-terminal domain of cardiac CaV1.2 channels during betal-adrenergic regulation. Proc Natl Acad Sci USA. 2006;103: 16574-9.

105. Chen L, Marquardt ML, Tester DJ, Sampson KJ, Ackerman MJ, Kass RS. Mutation of an A-kinase-anchoring protein causes long-QT syndrome. Proceedings of the National Academy of Sciences of the United States of America. 2007;104:20990-5.

106. El Refaey MM, Mohler PJ. Ankyrins and Spectrins in Cardiovascular Biology and Disease. Front Physiol. 2017;8:852.

107. Koenig SN, Mohler PJ. The evolving 
role of ankyrin-B in cardiovascular disease. Heart Rhythm. 2017;14:1884-9.

108. Towbin JA, McKenna WJ, Abrams DJ, et al. 2019 HRS expert consensus statement on evaluation, risk stratification, and management of arrhythmogenic cardiomyopathy. Heart Rhythm. 2019;16:e301-e72.

109. Corrado D, Wichter T, Link MS, et al. Treatment of Arrhythmogenic Right Ventricular Cardiomyopathy/ Dysplasia: An International Task Force Consensus Statement. Circulation. 2015; 132:441-53.

110. Protonotarios A, Anastasakis A, Panagiotakos DB, et al. Arrhythmic risk assessment in genotyped families with arrhythmogenic right ventricular cardiomyopathy. Europace. 2016;18: 610-6.

111. Alcalde M, Campuzano O, SarquellaBrugada $G$, et al. Clinical interpretation of genetic variants in arrhythmogenic right ventricular cardiomyopathy. Clin Res Cardiol. 2015;104:288303.

112. Pilichou K, Thiene G, Bauce B, et al. Arrhythmogenic cardiomyopathy. Orphanet J Rare Dis. 2016;11:33.

113. Bhonsale A, Groeneweg JA, James $\mathrm{CA}$, et al. Impact of genotype on clinical course in arrhythmogenic right ventricular dysplasia/cardiomyopathyassociated mutation carriers. Eur Heart J. 2015;36:847-55.

114. Groeneweg JA, Bhonsale A, James $\mathrm{CA}$, et al. Clinical Presentation, LongTerm Follow-Up, and Outcomes of 1001 Arrhythmogenic Right Ventricular Dysplasia/Cardiomyopathy Patients and Family Members. Circ Cardiovasc Genet. 2015;8:437-46.

115. Hoorntje ET, Te Rijdt WP, James CA, et al. Arrhythmogenic cardiomyopathy: pathology, genetics, and concepts in pathogenesis. Cardiovascular Research. 2017;113:1521-31.

116. Garcia-Gras E, Lombardi R, Giocondo MJ, et al. Suppression of canonical Wnt/beta-catenin signaling by nuclear plakoglobin recapitulates phenotype of arrhythmogenic right ventricular cardiomyopathy. J Clin Invest. 2006;116: 2012-21.

117. Elliott P, O'Mahony C, Syrris P, et al. Prevalence of desmosomal protein gene mutations in patients with dilated cardiomyopathy. Circ Cardiovasc Genet. 2010;3:314-22.

118. van Hengel J, Calore M, Bauce B, et al. Mutations in the area composita protein alphaT-catenin are associated with arrhythmogenic right ventricular cardiomyopathy. Eur Heart J.
2013;34:201-10.

119. Mayosi BM, Fish M, Shaboodien G, et al. Identification of Cadherin 2 (CDH2) Mutations in Arrhythmogenic Right Ventricular Cardiomyopathy. Circ Cardiovasc Genet. 2017;10.

120. Krahn AD, Deyell MW, Bastiaenen R. Arrhythmogenic right ventricular cardiomyopathy: From pathophysiology to diagnosis and advances in management. Cardiogenetics. 2017;7.

121. Oomen A, Semsarian C, Puranik R, Sy RW. Diagnosis of Arrhythmogenic Right Ventricular Cardiomyopathy: Progress and Pitfalls. Heart Lung Circ. 2018;27:1310-7.

122. Calkins H, Corrado D, Marcus F. Risk Stratification in Arrhythmogenic Right Ventricular Cardiomyopathy. Circulation. 2017;136:2068-82.

123. Merner ND, Hodgkinson KA, Haywood AF, et al. Arrhythmogenic right ventricular cardiomyopathy type 5 is a fully penetrant, lethal arrhythmic disorder caused by a missense mutation in the TMEM43 gene. Am J Hum Genet. 2008;82:809-21.

124. Kaski JP, Norrish G. Risk of sudden cardiac death in childhood hypertrophic cardiomyopathy: Time to solve the mystery. Cardiogenetics. 2018;8.

125. Limongelli G, Monda E, Tramonte S, et al. Prevalence and clinical significance of red flags in patients with hypertrophic cardiomyopathy. Int J Cardiol. 2020;299:186-91.

126. Frisso G, Limongelli G, Pacileo G, et al. A child cohort study from southern Italy enlarges the genetic spectrum of hypertrophic cardiomyopathy. Clinical Genetics. 2009;76:91-101.

127. Girolami F, Frisso G, Benelli M, et al. Contemporary genetic testing in inherited cardiac disease: tools, ethical issues, and clinical applications. J Cardiovasc Med (Hagerstown). 2018;19:1-11.

128. Marian AJ, Braunwald E. Hypertrophic Cardiomyopathy: Genetics, Pathogenesis, Clinical Manifestations, Diagnosis, and Therapy. Circ Res. 2017;121:749-70.

129. Ho CY, Charron P, Richard P, Girolami F, Van Spaendonck-Zwarts KY, Pinto Y. Genetic advances in sarcomeric cardiomyopathies: state of the art. Cardiovasc Res. 2015;105:397-408.

130. Biagini E, Olivotto I, Iascone M, et al. Significance of sarcomere gene mutations analysis in the end-stage phase of hypertrophic cardiomyopathy. Am J Cardiol. 2014;114:769-76.

131. Limongelli G, Masarone D, Frisso G, et al. Clinical and genetic characteriza- tion of patients with hypertrophic cardiomyopathy and right atrial enlargement. Journal of Cardiovascular Medicine. 2017;18:249-54.

132. Mademont-Soler I, Mates J, Yotti R, et al. Additional value of screening for minor genes and copy number variants in hypertrophic cardiomyopathy. Plos One. 2017;12.

133. Knoll R, Buyandelger B, Lab M. The Sarcomeric Z-Disc and ZDiscopathies. Journal of Biomedicine and Biotechnology. 2011.

134. Walsh R, Buchan R, Wilk A, et al. Defining the genetic architecture of hypertrophic cardiomyopathy: re-evaluating the role of non-sarcomeric genes. Eur Heart J. 2017;38:3461-8.

135. Mademont-Soler I, Mates J, Yotti R, et al. Additional value of screening for minor genes and copy number variants in hypertrophic cardiomyopathy. Plos One. 2017;12:e0181465.

136. Hershberger RE, Morales A, Siegfried JD. Clinical and genetic issues in dilated cardiomyopathy: a review for genetics professionals. Genet Med. 2010;12: 655-67.

137. Tabish AM, Azzimato V, Alexiadis A, Buyandelger B, Knoll R. Genetic epidemiology of titin-truncating variants in the etiology of dilated cardiomyopathy. Biophys Rev. 2017;9:207-23.

138. Hershberger RE, Morales A, Siegfried JD. Clinical and genetic issues in dilated cardiomyopathy: a review for genetics professionals. Genetics in Medicine. 2010;12:655-67.

139. McNally EM, Mestroni L. Dilated Cardiomyopathy: Genetic Determinants and Mechanisms. Circulation Research. 2017;121:731-48.

140. Lakdawala NK, Funke BH, Baxter S, et al. Genetic testing for dilated cardiomyopathy in clinical practice. J Card Fail. 2012;18:296-303.

141. Hershberger RE, Hedges DJ, Morales A. Dilated cardiomyopathy: the complexity of a diverse genetic architecture. Nat Rev Cardiol. 2013;10:531-47.

142. Japp AG, Gulati A, Cook SA, Cowie MR, Prasad SK. The Diagnosis and Evaluation of Dilated Cardiomyopathy. J Am Coll Cardiol. 2016;67: 2996-3010.

143. Favalli V, Serio A, Grasso M, Arbustini E. Genetic causes of dilated cardiomyopathy. Heart. 2016;102:2004-14.

144. Zhao Y, Feng Y, Zhang YM, et al. Targeted next-generation sequencing of candidate genes reveals novel mutations in patients with dilated cardiomyopathy. Int J Mol Med. 2015;36:147986. 
145. LeWinter MM, Granzier HL. Cardiac titin and heart disease. J Cardiovasc Pharmacol. 2014;63:207-12.

146.Zhou C, Li C, Zhou B, et al. Novel nesprin-1 mutations associated with dilated cardiomyopathy cause nuclear envelope disruption and defects in myogenesis. Hum Mol Genet. 2017;26:2258-76.

147. Tesson F, Saj M, Uvaize MM, Nicolas H, Ploski R, Bilinska Z. Lamin A/C mutations in dilated cardiomyopathy. Cardiol J. 2014;21:331-42.

148. Captur G, Arbustini E, Bonne G, et al. Lamin and the heart. Heart. 2018;104: 468-79.

149. Forleo C, Carmosino M, Resta N, et al. Clinical and functional characterization of a novel mutation in lamin a/c gene in a multigenerational family with arrhythmogenic cardiac laminopathy. PLoS One. 2015;10:e0121723.

150. Paller MS, Martin CM, Pierpont ME. Restrictive cardiomyopathy: an unusual phenotype of a lamin A variant. ESC Heart Fail. 2018;5:724-6.

151. Lazzarini E, Jongbloed JD, Pilichou K, et al. The ARVD/C genetic variants database: 2014 update. Hum Mutat. 2015;36:403-10.

152. Arbustini E, Pasotti M, Pilotto A, et al. Desmin accumulation restrictive cardiomyopathy and atrioventricular block associated with desmin gene defects. Eur J Heart Fail. 2006;8:47783.

153. Garcia-Pavia P, Cobo-Marcos M, Guzzo-Merello G, et al. Genetics in dilated cardiomyopathy. Biomark Med. 2013;7:517-33.

154. Mazzaccara C, Limongelli G, Petretta $\mathrm{M}$, et al. A common polymorphism in the SCN5A gene is associated with dilated cardiomyopathy. Journal of Cardiovascular Medicine. 2018;19:
344-50

155. Sabater-Molina M, Perez-Sanchez I, Hernandez Del Rincon JP, Gimeno JR. Genetics of hypertrophic cardiomyopathy: A review of current state. Clinical Genetics. 2018;93:3-14.

156. Hof IE, van der Heijden JF, Kranias EG, et al. Prevalence and cardiac phenotype of patients with a phospholamban mutation. Neth Heart J. 2019;27:64-9.

157. Staab J, Ruppert V, Pankuweit S, Meyer T. Polymorphisms in genes encoding nonsarcomeric proteins and their role in the pathogenesis of dilated cardiomyopathy. Herz. 2012;37:83641.

158. Vatta M, Faulkner G. Cytoskeletal basis of ion channel function in cardiac muscle. Future Cardiol. 2006;2:46776.

159. Sadeghi A, Doyle AD, Johnson BD. Regulation of the cardiac L-type $\mathrm{Ca} 2+$ channel by the actin-binding proteins alpha-actinin and dystrophin. Am J Physiol Cell Physiol. 2002;282:C150211.

160. McKenna WJ, Maron BJ, Thiene G. Classification, Epidemiology, and Global Burden of Cardiomyopathies. Circulation Research. 2017;121:72230.

161. Care M, Chauhan V, Spears D. Genetic Testing in Inherited Heart Diseases: Practical Considerations for Clinicians. Curr Cardiol Rep. 2017;19:88.

162. D'Argenio V, Frisso G, Precone V, et al. DNA sequence capture and nextgeneration sequencing for the molecular diagnosis of genetic cardiomyopathies. J Mol Diagn. 2014;16:32-44.

163. Tiziano FD, Palmieri V, Genuardi M, Zeppilli P. The Role of Genetic Testing in the Identification of Young Athletes with Inherited Primitive Cardiac
Disorders at Risk of Exercise Sudden Death. Front Cardiovasc Med. 2016; 3:28.

164. D'Argenio V, Esposito MV, Nunziato $M$, et al. Molecular diagnosis of Brugada syndrome via next-generation sequencing of a multigene panel in a young athlete. Medicina Dello Sport. 2018;71:27-34.

165. Maron BJ, Thompson PD, Ackerman $\mathrm{MJ}$, et al. Recommendations and considerations related to preparticipation screening for cardiovascular abnormalities in competitive athletes: 2007 update: a scientific statement from the American Heart Association Council on Nutrition, Physical Activity, and Metabolism: endorsed by the American College of Cardiology Foundation. Circulation. 2007;115:1643-455.

166. Corrado D, Pelliccia A, Bjornstad HH, et al. Cardiovascular pre-participation screening of young competitive athletes for prevention of sudden death: proposal for a common European protocol. Consensus Statement of the Study Group of Sport Cardiology of the Working Group of Cardiac Rehabilitation and Exercise Physiology and the Working Group of Myocardial and Pericardial Diseases of the European Society of Cardiology. Eur Heart J. 2005;26:516-24.

167. Pelliccia A, Adami PE, Quattrini F, et al. Are Olympic athletes free from cardiovascular diseases? Systematic investigation in 2352 participants from Athens 2004 to Sochi 2014. Br J Sports Med. 2017;51:238-43.

168. Gray B, Semsarian C. Utility of genetic testing in athletes. Clin Cardiol. 2020. 